Article

\title{
Fast and Inexpensive Detection of Bacterial Viability and Drug Effectiveness through Metabolic Monitoring
}

\author{
Sondos Ayyash ${ }^{1}$, Wen-I $\mathrm{Wu}^{2}$ and Ponnambalam Ravi Selvaganapathy ${ }^{1,2, *}$ \\ 1 School of Biomedical Engineering, McMaster University, Hamilton, ON L8S 4K1, Canada; \\ ayyashs@mcmaster.ca \\ 2 Department of Mechanical Engineering, McMaster University, Hamilton, ON L8S 4L7, Canada; \\ wuwing@gmail.com \\ * Correspondence: selvaga@mcmaster.ca; Tel.: +1-905-525-9140 (ext. 27435)
}

Academic Editors: Fan-Gang Tseng and Tuhin Subhra Santra

Received: 5 August 2016; Accepted: 26 October 2016; Published: 9 November 2016

\begin{abstract}
Conventional methods for the detection of bacterial infection such as DNA or immunoassays are expensive, time consuming, or not definitive and thus may not provide all the information sought by medical professionals. In particular, it is difficult to obtain information about viability or drug effectiveness, which is crucial to formulate a treatment. Bacterial culture tests are the "gold standard" because they are inexpensive and do not require extensive sample preparation, and most importantly, provide all the necessary information sought by healthcare professionals, such as bacterial presence, viability and drug effectiveness. These conventional culture methods, however, have a long turnaround time, anywhere between 1 day and 4 weeks. Here, we solve this problem by monitoring the growth of bacteria in thousands of nanowells simultaneously to more quickly identify their presence in the sample and their viability. The segmentation of a sample with low bacterial concentration into thousands of nanoliter wells digitizes the samples and increases the effective concentration in those wells that contain bacteria. We monitor the metabolism of aerobic bacteria by using an oxygen-sensitive fluorophore, ruthenium tris ( $2,2^{\prime}$-diprydl) dichloride hexahydrate (RTDP), which allows us to monitor the dissolved oxygen concentration in the nanowells. Using E. coli K12 as a model pathogen, we demonstrate that the detection time of $E$. coli can be as fast as 35-60 min with sample concentrations varying from $10^{4}$ (62 $\mathrm{min}$ for detection), $10^{6}\left(42 \mathrm{~min}\right.$ ) and $10^{8}$ cells $/ \mathrm{mL}$ (38 min). More importantly, we also demonstrate that reducing the well size can reduce the detection time. Finally we show that drug effectiveness information can be obtained in this format by loading the wells with the drug and monitoring the metabolism of the bacteria. The method that we have developed is low cost, simple, requires minimal sample preparation and can potentially be used with a wide variety of samples in a resource-poor setting to detect bacterial infections such as tuberculosis.
\end{abstract}

Keywords: bacterial culture; microfluidics; sample segmentation; metabolic monitoring; rapid analysis

\section{Introduction}

Infectious diseases caused by protozoa, bacteria, fungi and viruses are a leading cause of human suffering globally. According to the World Health Organization, infectious diseases claim 16.7 million lives worldwide each year [1]. Annually, an estimated 16 percent of all deaths worldwide result from infectious diseases [2]. Bacterial infectious diseases are responsible for a significant portion of these deaths. Some of the deadliest bacterial diseases include tuberculosis (1.5 million deaths worldwide in 2013) [3], syphilis (113,000 deaths worldwide in 2010) [4] and streptococcus $(826,000$ deaths worldwide) [5] just to name a few. 
Despite being curable and the availability of medicines for these diseases, the global morbidity and mortality rates remain high [6]. It should be noted that while treatment for many of these conditions is inexpensive, its diagnosis and identification of a suitable treatment is not. For instance, although tuberculosis can be treated and cured, there still remains a high rate of TB-related deaths worldwide. WHO reports that over $95 \%$ of tuberculosis deaths occur in low- and middle-income countries [5]. Thus, the development of an inexpensive diagnostic technique is key to addressing the number of cases of reported deaths caused by bacterial infectious diseases in resource-poor settings.

Bacterial detection methods can have far reaching applications beyond diagnosis, such as monitoring contamination in food and water. Thus, the identification of microbial contamination on meat $[7,8]$ microbial pathogens in water [9], improving patient care and preventing the spread of disease [10-12] are all areas that would benefit from a fast and low-cost bacterial detection method.

The current "gold standard" for bacterial disease diagnostics [13] is the bacterial culture test, a 120-year-old method [14]. This technique is still used in many resource-poor settings for the diagnosis of infectious diseases, as it is widely available, easy to handle, and inexpensive [14]. Using a selective medium that promotes the growth of specific bacteria, the conventional culture test method is able to provide information on the presence, viability and drug effectiveness of that bacteria [15]. All of this information is crucial for healthcare professionals in diagnosis and in formulating a treatment. However, it takes a long time, as visualization of a colony by eye is the threshold for detection. For instance, it is known to take 2-6 weeks for visual detection of the presence of tuberculosis colonies on the surface of a culture plate [16]. Even E. coli, a fast growing bacterium, requires a day of culture. Due to this disadvantage, molecular diagnostic methods including DNA biosensors, DNA chips [17], immunoassays (ELISA), and nucleic acid assays (PCR) [18] have been developed. They are faster than the culture test but are expensive [19], require extensive sample preparation [20] or may not provide all the information such as viability [21-23] and drug effectiveness [19] sought by doctors in diagnosing a disease and formulating a treatment. Another kind of bacterial detection based on biological detection by optical oxygen sensing, known as fluorescence-based respirometric screening technology (RST) [24,25], allows convenient high-throughput analysis of oxygen consumption by cells, but it is not able to perform rapid diagnostics especially when the concentration levels of bacteria are very small. For instance, it still takes $6-8 \mathrm{~h}$ for detection of $10^{4}$ cells $/ \mathrm{mL}$ of $E$. coli using RST while

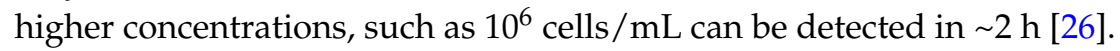

Here, we use metabolic monitoring of the growth of bacteria in nanoliter well arrays to increase the speed of detection of bacteria, its viability and its drug effectiveness. We demonstrate rapid detection of the growth $\left(\sim 1 \mathrm{~h}\right.$ for $10^{4}$ cells $\left./ \mathrm{mL}\right)$ and show that detection is faster when nanowells are smaller. We also demonstrate that minimal sample preparation is required for this method, making it suitable for resource-poor settings. This method could be a viable alternative to the current culture method and could be easily implemented in a wide variety of settings.

\section{Working Principle}

At its fundamental level, bacterial culture is a simple yet robust method to identify that a particular organism is alive (viable) and to visualize it to the naked eye through amplification (colony growth). Our visual resolution then determines the smallest colony that we can see and hence the time for detection of growth.

However, there are other methods that one could use to determine viability and growth. Any organism that is alive will consume nutrients and excrete waste. Thus, by measuring the material that is consumed or excreted, one could have an early indicator of the viability of the bacteria even before it has divided and grown sufficiently to be visually noticed. This is the principle behind the metabolic monitoring of culture as a generic method to measure the state of health of the organism. Specificity is provided by the use of selective growth media that only allows the growth of specific bacteria. An example of selective media is Middlebrook broth mixed with antibiotics, which is used to kill all other bacteria other than mycobacteria and is used in the detection of tuberculosis [27]. 
In this paper, we devise a method to detect the bacteria faster by measuring oxygen consumption (metabolic marker). The device consists of an array of nanoliter wells, which is fabricated using soft lithography as shown in Figure 1a. The inside surfaces of the wells are made hydrophilic while the top surface is made hydrophobic. Due to this configuration of surface properties, a sample dispensed and spread on the device will quickly fill the wells, automatically partitioning the sample into thousands of equal-sized nanoliter volumes.

The sample is mixed with an optical, oxygen-quenching fluorophore (RTDP) as well as selective medium [28] that facilitates growth of only the specific bacteria of interest. This is accomplished prior to dispensing it onto the surface of the device containing an array of nanowells (Figure 1b). A glass slide is then swiped across the surface (like a squeegee), which allows the bacterial solution to deposit and compartmentalize into the specific wells (Figure 1b).

Once compartmentalization of liquids within the defined wells is completed, a glass slide seals the filled nanowells to prevent evaporation of the sample (Figure 1b). The sealed device is then imaged through a fluorescent microscope or microarray scanner to measure the fluorescent intensity (metabolic measure of oxygen) changes over time (Figure 1b). Since bacteria are aerobic, they consume oxygen that is present in the medium during metabolism and deplete the oxygen in the surrounding environment, producing fluorescence. The separation distance between the nanowells is determined by the permeability of the material to oxygen over the duration of the detection. Drug effectiveness can also be probed by adding the appropriate drug to the broth and measuring growth or lack of it through fluorescence.

The segmentation of the sample into thousands of individual nanoliter wells digitizes the sample and has some benefits. Consider a typical sample that is several hundred nanoliters in volume contain a certain concentration of bacteria. At high concentrations, the concentration of bacteria in each well is the same as the overall concentration of the sample. However, at low concentrations, if the sample were segmented into thousands of smaller volumes then some of the wells will contain the bacteria of interest while others will not. The process of digitization of the samples creates some wells where the local concentration of bacteria is several times higher than the overall concentration in the sample and others where there would be no bacteria. Therefore, by digitizing the sample and measuring the metabolic markers in each of the wells simultaneously, one could arrive at detection of the bacteria much faster than in a larger homogeneous sample. This is the working principle behind our fast metabolic monitoring of bacteria.

A similar segmentation can be achieved in a digital droplet microfluidic platform [29]. However it requires sophisticated instrumentation for droplet generation compared to the method here and may not be suitable for resource-poor settings. Furthermore, the high permeability of the oil barrier to gases precludes it from use when the metabolic marker is oxygen.

Large scale arrays of nanowells have been used in the past for single cell imaging and analysis [30] and analyzing cytoplasmic contents of individual cells [31]. Recently, it has been used to perform end-point ELISA type immunoassays in the nanowell format for identification of mycobacteria [32]. However, ELISA requires extensive sample preparation for analysis, which is not only labor intensive but also a time-consuming. Also, endpoint assay typically requires that the assay duration be set for the minimum detectable concentration, as the concentration present in the sample is not known a priori.

Here we report a generic method that uses nanoliter well arrays to perform real-time measurement of oxygen as a metabolic marker to detect viability, growth and drug effectiveness of bacteria. The method requires very simple sample preparation that is suitable for resource-poor settings. Real-time measurements allow faster detection of growth especially when the concentrations are higher than a single bacteria/well. The instrumentation required for imaging and fluorescent measurements can also be made simpler and cost-effective using some of the recent developments in low cost optics [33,34]. In combination, this approach provides an effective method for fast culture-based detection in resource-poor settings. 
(i)

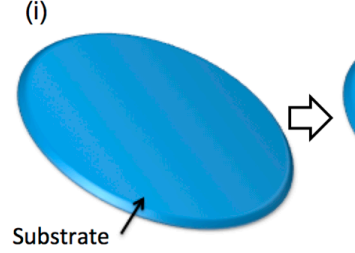

(ii)

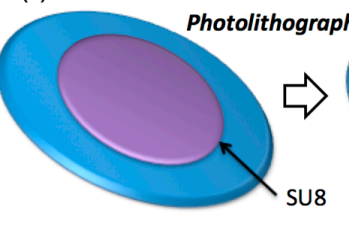

(iii)

(iv)

(v)
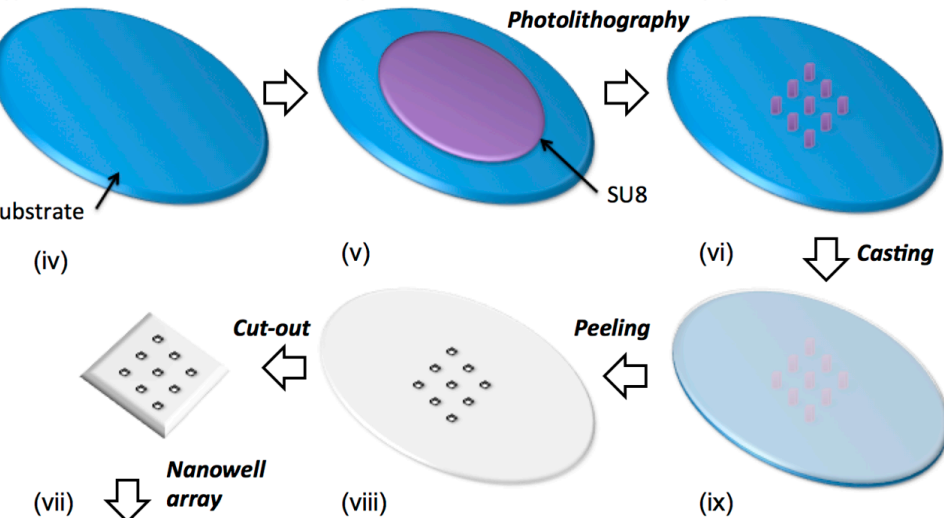

(vi) 凸Casting

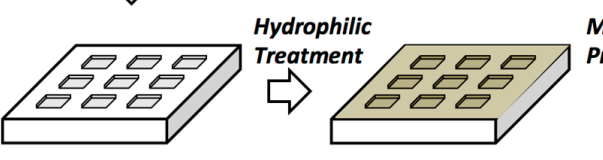

(ix)

Micro-contact

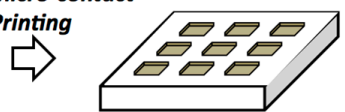

(a)

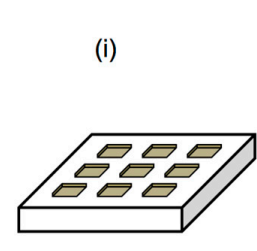

(vi)

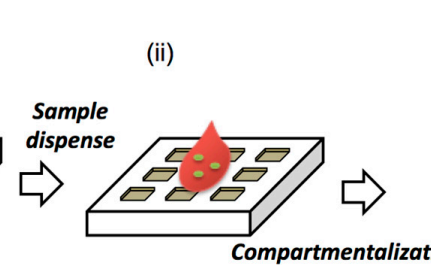

(v)

(iii)

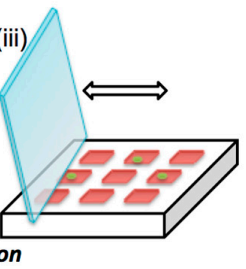

(iv)

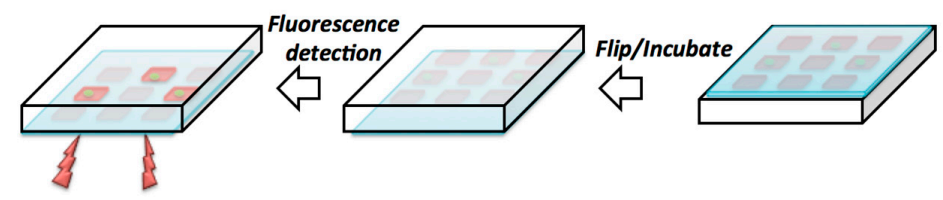

(b)

Figure 1. Schematic representation of the (a) soft lithography and surface modification process to fabricate the device and (b) sequence of operation of the device.

\section{Materials and Methods}

Materials. Silicon wafers (mechanical grade, $3^{\prime \prime}, 500 \mu \mathrm{m}$ thick) were purchased from University Wafer Co., USA. Negative photoresist Su8-100 and developer were acquired from Microchem Co., USA. PDMS polymer was purchased from Dow Corning Co., Canada. The powder of RTDP (ruthenium tris (2,2'-dipyridyl) dichloride hexahydrate) was obtained from Sigma-Aldrich (\#224758). Liquid microbial growth medium, Luria Broth (LB) purchased from Sigma-Aldrich (\#L2542). The hydrophilic surface modification agent (N-Wet 410) was gifted by Enroute Interfaces Inc., and one part of the n-Wet 410 solution was diluted with 9 parts of toluene giving a final concentration of $10 \% \mathrm{~V} / \mathrm{V}$. Glass slides (Corning, $75 \times 25 \times 1 \mathrm{~mm}$ ) were used to sandwich our device. A commercial hydrophobic surface modification agent, Aquapel was obtained from Aquapel ${ }^{\circledR}$ Glass Treatment, and was used to make glass slides hydrophobic. Methylcellulose MC (M-0262) viscosity of $2 \%$ aqueous solution at $20^{\circ} \mathrm{C}$, 400 centipoises was obtained from Sigma.

Microfabrication of nanowell array. SU-8 100 photoresist is spun on a Silicon wafer at $3000 \mathrm{rpm}$ to produce a layer of $100 \mu \mathrm{m}$ thickness (Figure 1a(ii)). This layer was patterned using photolithography and produced square or circular shapes of sizes that varied from 100-1000 $\mu \mathrm{m}$ to produce the mold for nanowell devices (Figure 1a(iii)). Next, polydimethylsiloxane (PDMS) prepolymer (base:curing 
agent $=10: 1)$ was cast on the mold, cured and peeled off to replicate the pattern of the mold forming an array of nanoliter wells as shown in Figure 1a(iv). Next, the cast and crosslinked PDMS elastomer is peeled off and cut to the required shape. Subsequently, the device is immersed and left overnight into the n-Wet 410 solution to modify the entire surface of the PDMS to a hydrophilic state (Figure 1a(viii)). Finally, the top surface of the device is microcontact stamped with a thin layer of PDMS prepolymer and cross linked in order to make only that surface hydrophobic (Figure 1a(ix)).

Experimental procedure. During experiments $0.01 \mathrm{~mL}$ sample solution containing bacteria is dispensed on the surface (Figure $1 \mathrm{~b}(\mathrm{ii})$ ). Next, a glass slide is used as a squeegee to move the liquid around on the surface. The sample liquid automatically enters and compartmentalize into the nanowells as it is moved around (Figure $1 \mathrm{~b}$ (iii)). The device is then sealed with a glass slide coated using a commercial hydrophobic surface modification agent (Aquapel ${ }^{\circledR}$ ) and imaged under a microscope to measure the fluorescence intensity of the oxygen quenching fluorophore. A confocal microscope was used throughout the experiments to capture images, whereby the E. coli is located on a specific plane, and thus, the fluorescence of the RTDP is obtained along the same location for the remainder of the experiment. Each experiment was repeated for a minimum of three times; however, the majority of experiments were repeated nearly six times. Once experiments were completed, offline image analysis of the fluorescent intensity within the wells was calculated by using ImageJ (NIH, https://rsb.info.nih.gov/ij).

Data Analysis: The intensity was normalized to the initial intensity in the well for reporting purposes. For all the experiments, the initial intensity of the well was done by dividing the current intensity by the original intensity at $t=0$ to obtain the normalized increase in intensity at that time point.

Device dimensions. We have developed a microfluidic device that is $1-2 \mathrm{~cm}^{2}$ in size composed of an array of nanowells with diameters (100-1000 $\mu \mathrm{m})$, shape (circular, square), volume (1-100 nL) and a depth of $100 \mu \mathrm{m}$. The dimensions of the E. coli bacterium are $0.5 \times 2 \mu \mathrm{m}$, and thus the well size was selected to be large enough to have enough nutrients for a growing population, but small enough for fast detection rates.

Artificial sputum. The sputum was prepared by mixing 2\% (w/v) methylcellulose (Sigma M-0262) in $1000 \mathrm{~mL}$ of DI water [34], which resulted in a viscosity of $0.4 \mathrm{~Pa} \cdot \mathrm{s}$ at $20{ }^{\circ} \mathrm{C}$ [35]. This viscosity matched that of mucoid, which was reported by Maria Teresa Lopez-Vidriero et al [36] to be $0.42 \mathrm{~Pa} \cdot \mathrm{s}$.

Bacterial strains and growth conditions. E. coli strain (OP50 and K12) was used for this study. Cells were grown aerobically at $37^{\circ} \mathrm{C}$ in LB medium ( $10 \mathrm{~g}$ tryptone, $10 \mathrm{~g} \mathrm{NaCl}, 5 \mathrm{~g}$ Yeast extract per liter). Bacterial cells in stationary phase were harvested after overnight incubation. Plating based cell counting methods were used to determine the exact concentrations of the sample solutions.

\section{Results and Discussion}

\subsection{Sample Dispensing and Compartmentalization}

The sample dispensing technique was tested on a range of different nanowell sizes to determine which among them were filled with ease. Various sized nanowells in the range of $1 \mathrm{~nL}$ $(35 \times 35$ nanowells; 1225 nanowells in total $)$ to $100 \mathrm{~nL}(7 \times 7$ nanowells; 49 nanowells in total $)$ were fabricated, with a device area of $7.5 \times 7.5 \mathrm{~mm}$. The nanowells were either square or circular in cross-section and their feature size ranged between 100 to $1000 \mu \mathrm{m}$ : dimensions of: $225 \mu \mathrm{m}(5 \mathrm{~nL})$, $265 \mu \mathrm{m}(7 \mathrm{~nL}), 340 \mu \mathrm{m}(11.5 \mathrm{~nL}), 360 \mu \mathrm{m}(13 \mathrm{~nL}), 500 \mu \mathrm{m}(25 \mathrm{~nL})$, and $1000 \mu \mathrm{m}(100 \mathrm{~nL})$. The depth of the nanowells was kept constant at $100 \mu \mathrm{m}$. A single drop of liquid was portioned into hundreds of nanoliter-sized wells by dragging it along a surface with a hydrophobic coverslip. It is brushed onto the surface of the elastomer in the one direction (sideways) and then swiped back in the opposite direction. With each swipe, a certain percentage of wells are filled. The process of filling of the wells is demonstrated in Figure 2a. Here, nanowell arrays with $100 \mu \mathrm{m}(1 \mathrm{~nL})$ dimensions were filled with DI water mixed with methylene blue dye for visualization. 
Various well sizes were tested and the number of swipes required to completely fill all the wells in a particular design has been plotted in Figure $2 b(n=6)$. The sample liquid used was DI water with a viscosity of $0.001 \mathrm{~Pa} \cdot \mathrm{s}$. The results indicate that the wells were completely filled in all the designs with a maximum of 5 swipes. Since each of the swipes takes $\sim 10 \mathrm{~s}$, the entire device could be filled in under a minute with minimal instrumentation or technique. It was evident from the results shown in Figure $2 b$ that the larger sized nanowell $(100 \mathrm{~nL}-\mathrm{S} / \mathrm{V}$ ratio of 0.024$)$ filled slightly faster than the smaller sized nanowell array. The percentage of the wells filled was significantly different after one swipe and became nearly the same after multiple swipes. Filling the nanowells becomes a difficult task at much smaller scales, and evaporation becomes significant at $25 \mathrm{fL}$ as reported by Taylor and Walt [37].The difference in filling between the different sized wells in the range tested was not statistically significant $(p>0.5)$. Therefore, regardless of the size of the well, the array was filled in 3-5 swipes.

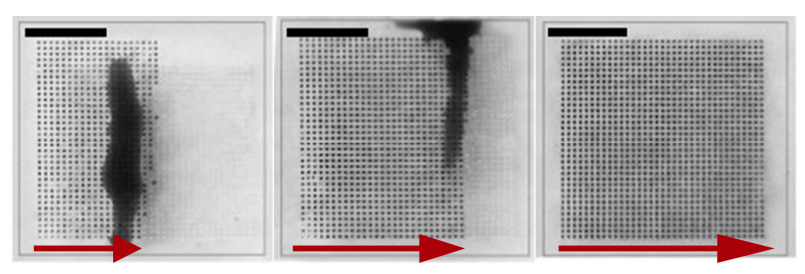

(a)

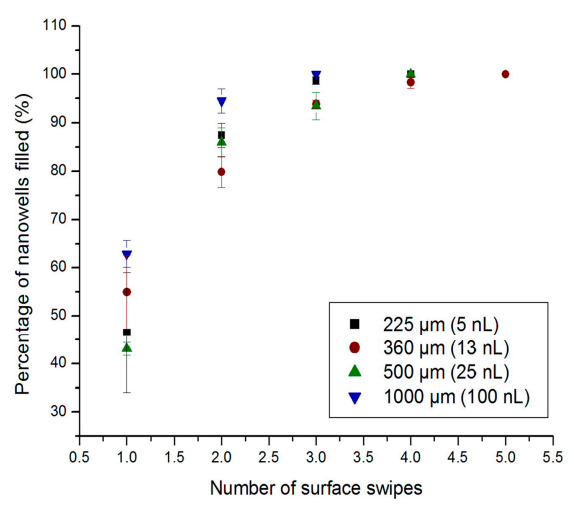

(b)

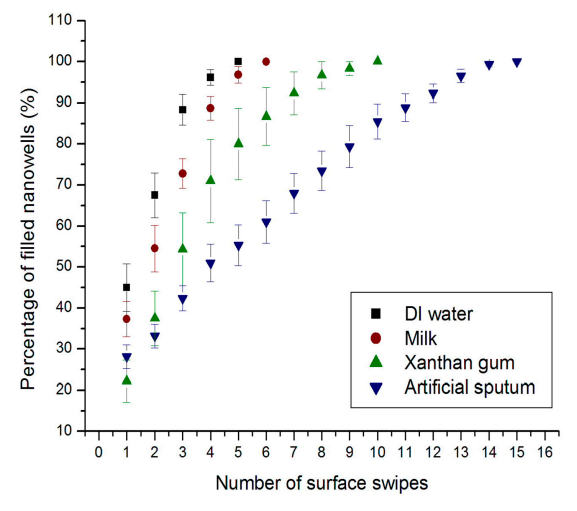

(c)

Figure 2. (a) Optical images of progressive filling of an array of $1 \mathrm{~nL}$ volumes with dimensions: $100 \mu \mathrm{m} \times 100 \mu \mathrm{m} \times 100 \mu \mathrm{m}$. A mixture of DI water and methylene blue is dispensed on the surface, whereby a glass coverslip is used as a squeegee to push the liquid from left to right until the entire matrix is filled. Scale bars, $2.5 \mathrm{~mm}$; (b) Percentage of nanowells of different volumes filled per swipe (with a coverslip) using a mixed solution of de-ionized water and methylene blue; (c) Percentage of wells filled with each swipe, of a $1 \mathrm{~nL}$ array, with solutions of different viscosities: DI water (0.001 Pa.s), milk (0.003 Pa.s), xanthan gum solution (non-Newtonian fluid), and artificial sputum (0.4 Pa.s).

The ability of the solution to compartmentalize within the nanowell array was also characterized using liquids of different viscosities ranging from water $\left(0.001 \mathrm{~Pa} \cdot \mathrm{s}\right.$ at $\left.20{ }^{\circ} \mathrm{C}\right)$ to high viscosity shear thinning liquids such as xanthan gum (59.96\% water $/ 40 \%$ glycerol $/ 0.04 \%$ xanthan gum) [38], protein rich solutions such as milk (viscosity of $0.003 \mathrm{~Pa} \cdot \mathrm{s}$ at $20{ }^{\circ} \mathrm{C}$ ) and artificial sputum $\left(0.4 \mathrm{~Pa} \cdot \mathrm{s}\right.$ at $20{ }^{\circ} \mathrm{C}$ ) [35]. These tests were conducted to mimic real samples such as blood (protein rich) or sputum (high viscosity) and their effect on compartmentalization in our device. The experimental results as shown in Figure 2c demonstrated that all the types of fluids used were able to fill the nanowells within a reasonable number of swipes. However, fluids with lower viscosities (DI water) compartmentalize and fill the entire array of nanowells more quickly (within 5 swipes) than fluids with higher viscosities (i.e., artificial sputum-15 swipes). The artificial sputum had nearly 400 times higher viscosity to 
DI water and filled only $50 \%$ of the wells at 5 swipes. This experiment demonstrates that viscosity of a solution is an important factor in the compartmentalization process. Nevertheless, since each swipe takes only $\sim 10 \mathrm{~s}$, the extra time required $(\sim 100 \mathrm{~s})$ is reasonable and can easily be accommodated within the sample preparation process. Protein rich solutions such as milk with viscosities similar to water, $0.003 \mathrm{~Pa} \cdot \mathrm{s}$, required an additional swipe compared to DI water. This result shows that high protein loading of the sample did not affect the compartmentalization and was not a significant factor in the filling of the nanowells as compared to viscosity. Xanthan gum diluted in water $(59.96 \%$ water/ $40 \%$ glycerol $/ 0.04 \%$ xanthan gum) [38] was used as a viscoelastic, shear-thinning blood analogue. It required 10 swipes to completely fill a nanowell array. This set of experiments demonstrated that viscosity of the sample solution is the key determinant in filling of the nanowells. It also showed that higher viscosity samples require higher number of swipes to fill. Finally, it demonstrated that a wide variety of sample types could be compartmentalized within a short time frame and without elaborate setup using our nanowell array.

\subsection{Distribution of Bacteria}

The distribution of the bacterial cells within an array of nanowells after dispensing was measured for various concentration of sample solution in order to identify if it is uniform. The sample solution used was Luria Broth (LB) media spiked with GFP expressing E. coli with concentrations of from $10^{4}$ to $10^{8}$ cells $/ \mathrm{mL}$. This sample was dispersed into a nanowell array that had well volumes of $1 \mathrm{~nL}$. A uniform and complete dispersion of the sample into the wells will then produce a population of 100 cells $/$ well at $10^{8}$ cells $/ \mathrm{mL}$ and 1 cell $/$ well at $10^{6}$ cells $/ \mathrm{mL}$. For a concentration of $10^{4}$ cells $/ \mathrm{mL}$, it is expected that about 1 out of 100 wells will contain bacterial cells. Three sets of dispensing experiments were performed on separate devices and 11 wells at random were measured in each of the devices. For the low concentration samples, 100 wells were measured. Bacterial population in each well was counted manually by taking confocal images at various depths in the nanowells. Figure 3a shows one such composite image where the GFP expressing bacteria was imaged as green dots inside the well. The oxygen sensitive fluorophore (RTDP) dispensed into the wells can be simultaneously imaged at a different wavelength (red). At the sample concentration of $10^{8}$ cells $/ \mathrm{mL}$, individual wells were found to contain $\sim 48$ cells/well with a standard deviation of 10 . Sample concentration of $10^{6}$ cells $/ \mathrm{mL}$ resulted in 4.5 cells / well with a standard deviation of 2.2 . Finally, at a concentration of $10^{4} \mathrm{cells} / \mathrm{mL}$ the bacterium was scattered and scarce, only to have 1 bacterium present in certain wells while many others contained no bacterium at all. The mean distribution of a concentration of $10^{4}$ cells $/ \mathrm{mL}$ was found to be 1 cell each in six separate wells out of 100 wells (6/100), with a standard deviation of 2.0. The populations at various concentrations of sample seem to correspond to their expected values to an order of magnitude. Distribution of the bacteria appeared to be uniform. Although a confocal microscope is used here to image and count the bacteria $(1 \mu \mathrm{m})$ at various levels within the nanowell for characterization purposes, the use of a metabolic marker which is distributed throughout the well ensures that a low resolution CCD imager can be used to measure intensity of the nanowells $(\sim 50 \mu \mathrm{m}$ in size) and through it identify the presence or absence of bacteria.

\subsection{Oxygen Sensing in Nanowells}

In order to determine the range of oxygen concentrations that can be sensed and the stability of the measurement technique, fluorescent sensing of oxygen concentration was carried out using samples prepared to have a known concentration of oxygen in them. First, an oxygen scavenger sodium sulphite, $5 \mathrm{~g} / \mathrm{L}$ was dissolved in LB media along with the fluorophore RTDP $(0.3 \mathrm{mg} / \mathrm{mL})$ to produce a sample with depleted of oxygen levels. Dissolved oxygen was measured using a commercial optical oxygen sensor (YSI 550A, YSI Environmental, Yellow Springs, OH, USA) which yielded a solution with an oxygen concentration of $0 \mathrm{mg} / \mathrm{L}$. A second sample was prepared by bubbling oxygen gas into the LB media, mixed with RTDP, to produce an oxygen concentration of $15.6 \mathrm{mg} / \mathrm{L}$. Finally, LB media exposed to ambient atmospheric condition was also tested. These samples were dispensed 
onto the nanowell array and intensity of fluorescence in the wells was observed over one hour as shown in Figure 3b. Each condition was repeated three different times, and 14 wells were analyzed and processed for each experiment.
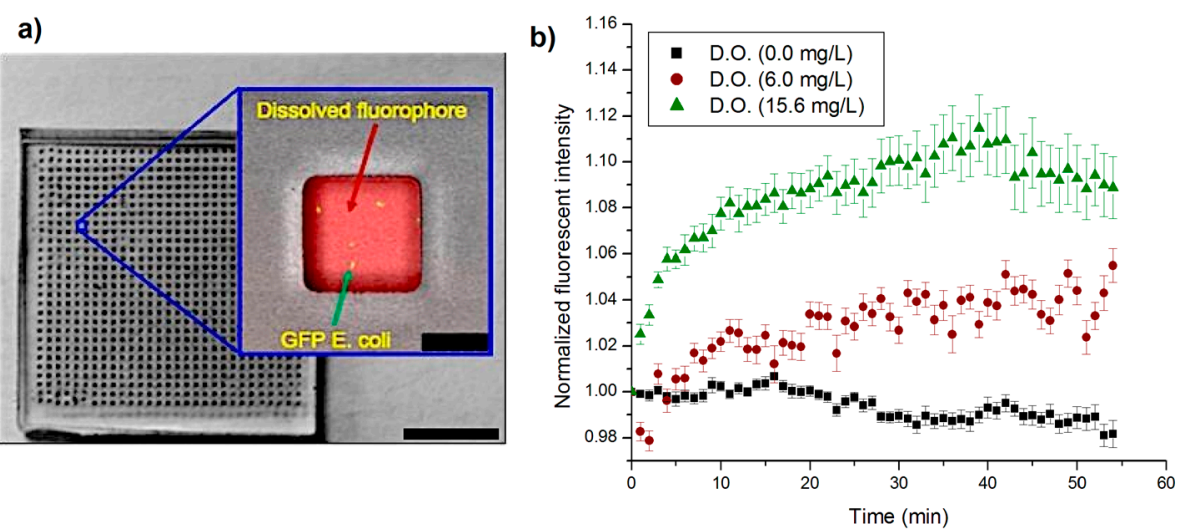

Figure 3. (a) Optical image of the nanowell array. The inset shows fluorescent image of a single well with both GFP expressing bacteria (green) and the oxygen sensitive fluorophore (red). The oxygen sensitive fluorophore is dispersed throughout the entire well and indicates the oxygen concentration in the entire well. The wells volume is $1 \mathrm{~nL}$. The GFP and RTDP fluorophore were imaged separately using a different combination of excitation and emission filters, and then overlaid to give a complete image with bright-field. Scale bar of device, $25.5 \mathrm{~mm}$. Scale bar of zoomed in well, $50 \mu \mathrm{m}$; (b) Normalized fluorescent intensity of nanowells over time for control samples. Control 1: High concentration $-\mathrm{O}_{2}$ gas bubbled into the solution $\left(\left[\mathrm{O}_{2}\right]=15.6 \mathrm{mg} / \mathrm{L}-24.3 \mathrm{AU}\right)$, Control 2: Atmospheric conditions $\left(\left[\mathrm{O}_{2}\right]=6 \mathrm{mg} / \mathrm{L}-30.1 \mathrm{AU}\right)$, and Control 3: Low concentration- oxygen scavenger is added $\left(\left[\mathrm{O}_{2}\right]=0 \mathrm{mg} / \mathrm{L}-66.2 \mathrm{AU}\right)$. Fluorescence intensities were normalized (to $\left.t=0\right)$ to allow direct comparison of fluorescent increases/decreases. $(n=3)$.

The results show that fluorescent intensity changes with oxygen concentration in the wells. For instance the intensity was 66.2 AU when the oxygen concentration was $0 \mathrm{mg} / \mathrm{L}$. 30.1 AU when the oxygen concentration was $6 \mathrm{mg} / \mathrm{L}$ and $24.3 \mathrm{AU}$ the oxygen concentration was $15.6 \mathrm{mg} / \mathrm{L}$. In the case of the sample with low initial oxygen concentration $(0 \mathrm{mg} / \mathrm{L})$, the intensity of fluorescence decreased over time. This is expected as Sodium sulfite scavenged the oxygen completely from the sample leading to a low concentration and a high initial fluorescent intensity of the sample. However, since PDMS is oxygen-permeable, a small flux of oxygen from the PDMS into the well would increase the overall oxygen concentration, which quenches the fluorophore leading to a reduction in its intensity. In the second case of the sample with high initial oxygen concentration $(15.6 \mathrm{mg} / \mathrm{L})$, the intensity of fluorescence increased over time. Oxygen bubbling produced high oxygen concentration, which quenched the fluorophore significantly, and the initial fluorescent intensity was very low. Over time some of the oxygen would diffuse out into the PDMS surrounding the sample, leading to lower overall concentration in the well and higher intensity. The increase or decrease in fluorescent intensity over time under these extreme conditions was found to be significantly small demonstrating that PDMS is an effective material to separate the sample from the ambient environment for metabolic monitoring. Finally, in the case of the sample solution exposed to ambient atmospheric conditions, it was found that the fluorescent intensity was nearly the same over long durations of time, indicating that any change in intensity would in subsequent experiments only be due to consumption processes inherent to the presence of bacteria in the wells.

\subsection{Growth of Bacteria in Nanowells}

It is important to determine that the bacteria grow over the intended duration of testing in the confines of the nanowells and that their growth is not restricted due to depletion of nutrients. In order 
to test this, a long duration growth study was performed where GFP expressing E. coli (10 ${ }^{5}$ cells $\left./ \mathrm{mL}\right)$ in LB media with the fluorophore was dispensed into the nanowell array (whereby each well contained a $1 \mathrm{~nL}$ volume) and observed over $12 \mathrm{~h}$. The results as shown in Figure 4 demonstrated significant growth of the bacteria with several rounds of division. At time $t=0$ (Figure $4 \mathrm{a}$ ) only a few isolated bacteria are observed. At time $t=12 \mathrm{~h}$ (Figure $4 \mathrm{~b}$ ) large colonies of bacteria originating from the initial single bacteria could be observed. It is interesting to note that the growth happens in a filamentous form as the E. coli divides along its length and since there is no disturbance in this particular microenvironment, the daughter cells were located right next to the mother cells. This experiment clearly shows that the volume of the nanowell is sufficiently large to allow growth and division of bacteria over a period of $12 \mathrm{~h}$ at least.

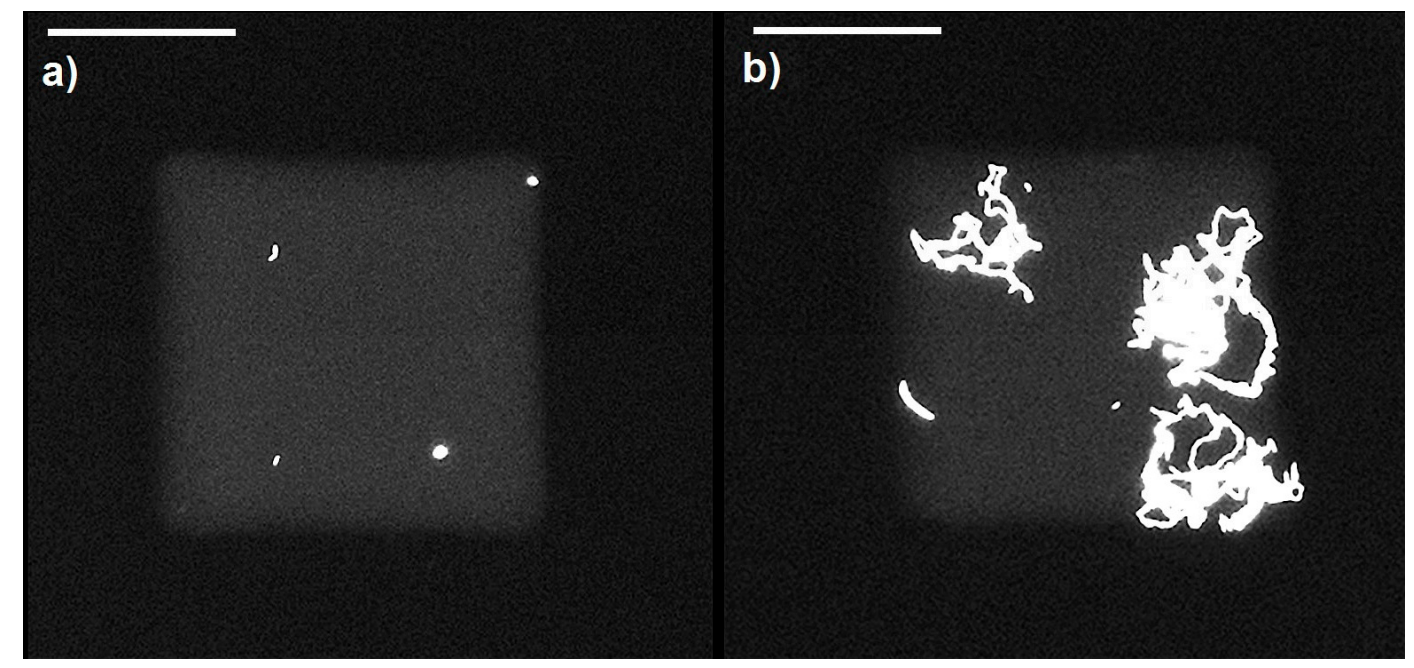

Figure 4. Fluorescent images of nanowells with GFP expressing bacteria E. coli K12 in LB media at different time points indicating growth of the bacteria in confined volumes. The well volume was $1 \mathrm{~nL}$. (a) Image at time $t=0 ;(\mathbf{b})$ image after $12 \mathrm{~h}$ of growth. Scale bars, $50 \mu \mathrm{m}$.

\subsection{Measurement of Metabolic Activity}

Fluorescent intensity corresponds to metabolic activity within the wells. Each bacterium consumes a certain amount of oxygen for its metabolism as long as it is viable. RTDP is oxygen-quenching, so the fluorescent intensity increases with oxygen depletion within nanowells. Thus fluorescent intensity in the nanowells can be used as a marker for viability of bacteria that is present in that well. In order to test this principle, sample solutions containing $10^{6}$ cells $/ \mathrm{mL}$ were loaded into a nanowell array with well volume of $1 \mathrm{~nL}$ and the fluorescent intensity in these wells imaged over time. Figure 5a shows the change in intensity between $t=0$ and $t=2.5 \mathrm{~h}$. A clear increase in intensity was observed, demonstrating that the metabolism of the bacteria in the solution can be observed using the intensity of the oxygen sensitive fluorophore in the nanowells. The intensity is also nearly uniform over the entire well indicating that a low resolution, low-cost imager can potentially be used for measuring the intensities. Next, in order to quantify the effect of bacterial concentration on the increase in intensity, sample solutions with various concentrations from $10^{4}$ to $10^{8}$ cells $/ \mathrm{mL}$ were dispensed into the wells and the change in intensity measured over time. Each concentration was repeated three times and in each case three wells were measured $(n=3)$. The wells were chosen from 3 different locations on the chip to get an average value over the entire chip. The results are presented in Figure $5 b$ and show that in all cases, an increase in intensity occurs over time due to the consumption of oxygen in the wells by the bacteria present in them. For instance, when the concentration of the bacteria was $10^{4} \mathrm{CFU} / \mathrm{mL}$, the intensity increased from 34.1 AU to 43.3 AU. Higher concentrations have a greater rate of increase in intensity indicating that the rate of consumption of oxygen was higher which is expected. Thus, when the concentration of bacteria was $10^{6} \mathrm{CFU} / \mathrm{mL}$ the intensity increased from $34.3 \mathrm{AU}$ to $43.5 \mathrm{AU}$. 
Similarly, at a concentration of $10^{8} \mathrm{CFU} / \mathrm{mL}$ the intensity increased from $43.0 \mathrm{AU}$ to $73.6 \mathrm{AU}$. These experiments indicate that the oxygen levels in the nanowells can be measured with an oxygen sensitive fluorophore RTDP that has high sensitivity, to monitor the metabolic activity of bacteria as well as quantify their concentration in sample solution.

a)

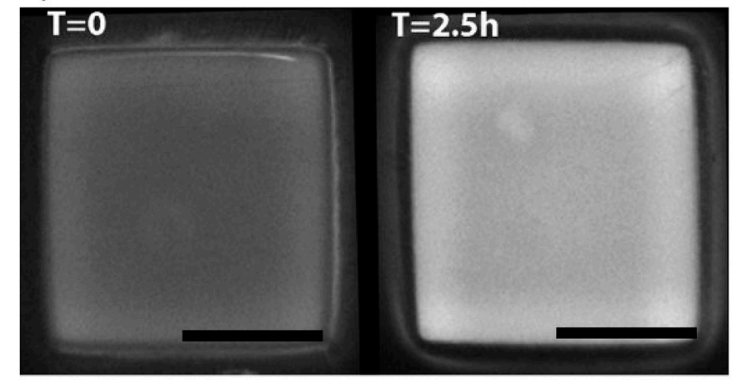

b)

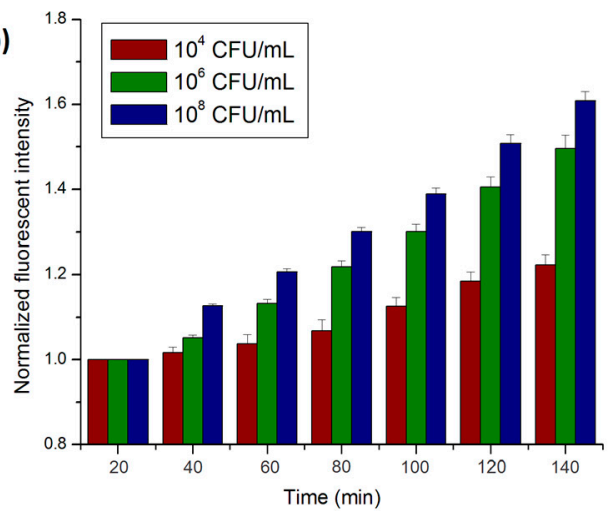

Figure 5. (a) Fluorescence images of nanowell containing a sample solution with a bacterial concentration of $10^{6} \mathrm{CFU} / \mathrm{mL}$ at time $t=0$ and after $2.5 \mathrm{~h}$ showing a clear increase in fluorescent intensity over time which is indicative of oxygen depletion due to bacterial metabolism. Scale bars, $50 \mu \mathrm{m}$; (b) Normalized fluoroscent intensity of the nanowells containing bacteria measured over time for various concentrations of bacteria. Fluorescence intensities were normalized (to $t=0$ ) to allow direct comparison of fluorescent increase $(n=3)$. The devices used had a well size of $1 \mathrm{~nL}$. Higher increases were observed when the concentration of bacteria in the wells were higher.

\subsection{Effect of Nanowell Size on Change in Intensity}

The size of the wells determines the amount of oxygen that is originally present in the wells, and consequently the time at which bacteria in a well can consume sufficient amount of oxygen to reduce the concentration sufficiently to make it measurable. This effect of the nanowell size is likely to be noticeable at low concentrations of bacteria. In order to quantify this effect, sample solutions with E. coli (K12 strain) at a concentration of $10^{4}$ cells $/ \mathrm{mL}$ were dispensed into devices with various well sizes of: $0.1 \mathrm{~mL}, 100 \mathrm{~nL}$ and $1 \mathrm{~nL}$ respectively. Three devices at each well size were tested and three wells were measured in each device. The fluorescent intensity in these wells was measured over time and the results are plotted in Figure 6a. It shows that the device with smallest sized wells $(1 \mathrm{~nL}$ volume) had the largest increase in fluorescent intensity (from 34.1 AU to $43.3 \mathrm{AU}$ ). In comparison, the device with $100 \mathrm{~nL}$ wells showed a slower rate of increase (from 29.1 AU to $34.5 \mathrm{AU}$ ) and those with $0.1 \mathrm{~mL}$ wells showed only a miniscule increase over time (from 27.4 AU to 29.0 AU). At a concentration of $10^{4}$ cells $/ \mathrm{mL}$, the population density of the bacteria in the wells for the various well volumes are: 100 's cells/well for $0.1 \mathrm{~mL}$ wells, $\sim 1$ cell/well for $100 \mathrm{~nL}$ and $<<1$ cell/well (or 1 well in a 100 are filled with one bacteria) for $1 \mathrm{~nL}$ wells. In the device with the $1 \mathrm{~nL}$ well, the effective concentration in those wells that have a bacteria is 1 cell $/ \mathrm{nL}$ or $10^{9}$ cells $/ \mathrm{mL}$ which is a 5 order of magnitude amplification in concentration due to segmentation of the sample. Therefore the bacteria in the nanowell can quickly deplete the oxygen present in the well and lead to faster detection. This also indicates that single cell detection is easily possible in this format. 

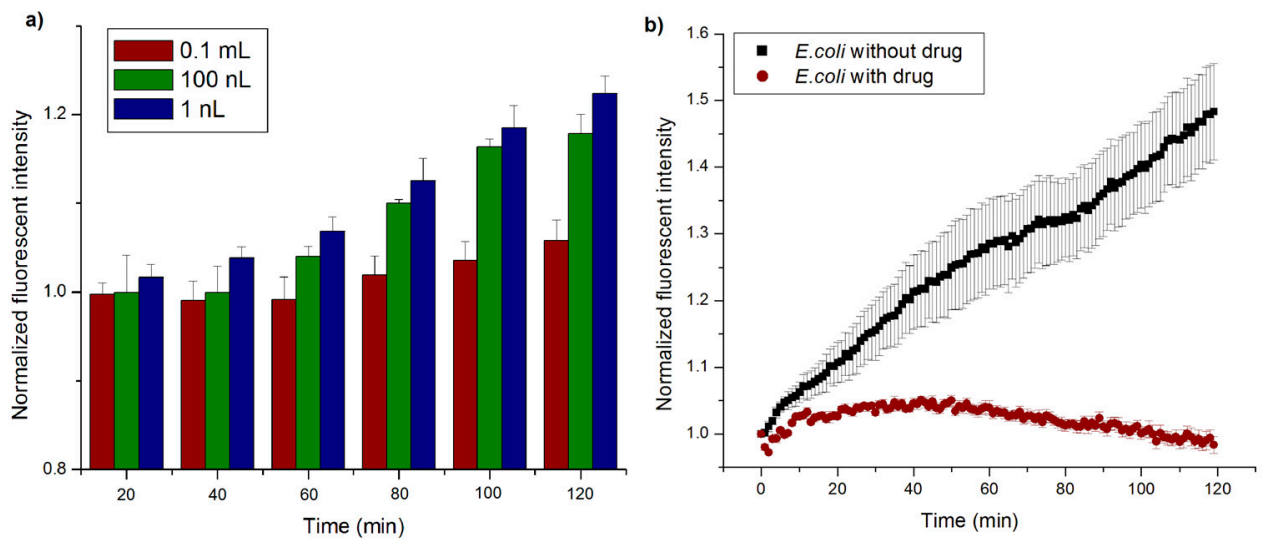

Figure 6. (a) Fluoroscence intensity in nanowells measured over time for various well volumes. Fluorescence intensities were normalized (to $t=0$ ) to allow direct comparison of fluorescent increases $(n=3)$. Smaller wells show a more significant intensity change corresponding to the rate of change of oxygen concentration in them; (b) Normalized fluoroscent intensity in nanowells measured over time in the presence and absence of ampicillin. The bacterial concentration used was $10^{6} \mathrm{CFU} / \mathrm{mL}$. Fluorescence intensities were normalized (to $t=0$ ) to allow direct comparison of fluorescent increases/decreases. $(n=3)$.

\subsection{Drug Effectiveness}

In many cases of bacterial infection such as tuberculosis, identification of drug effectiveness of the bacteria present in a particular sample quickly is of great importance to a physician in identifying the appropriate treatment [39]. The effectiveness of any drug on that particular infection can be identified by adding it along with the growth medium and determining if the bacteria in the patient sample stops growing and loses its viability. Thus by adding the drug to the growth medium before dispensing it into the nanowells and measuring metabolic changes in the bacteria from its oxygen consumption, one could measure the effect of the drugs impact on bacterial growth and survival. In order to test whether the effect of a drug on bacterial metabolism could be identified in this device, an experiment was performed where ampicillin, which is a drug known to inhibit the growth of E. coli OP50 strain, was loaded along with it. In the experiment, $5 \mathrm{mg} / \mathrm{L}$ of ampicillin, a concentration that is well above the minimum inhibitory concentration (MIC) of $2 \mathrm{mg} / \mathrm{L}$ [40], was added into a bacterial broth with a concentration of $10^{6}$ cells per $\mathrm{mL}$ to inhibit the cell growth. The control was the same experiment without the drug loaded, and was repeated thrice $(n=3)$. The profile of the increase in intensity with time is shown in Figure 6b. It appears that in the devices where ampicillin was added, the fluorescent intensity did not change significantly, indicating that the oxygen in those nanowells was not consumed. Antibiotics like ampicillin act as an irreversible inhibitor of the enzyme transpeptidase, which is essential in OP50 E. coli bacteria to make their cell walls and thereby inhibits growth. If the bacteria were sensitive to the drug, there should be no (or little) evident increase in fluorescent intensity, which signifies that there is no metabolic activity. Damaged and dead bacterial cells have lower innate metabolic activity, and thus will not consume oxygen. These results indicate that the ampicillin had the intended effect of preventing the growth and viability of the bacteria in the wells. The control on the other hand had a gradual and significant increase in intensity, indicating that under the same growth condition and in the absence of ampicillin the bacteria were viable. These experiments indicate that metabolic monitoring of the nanowells can provide crucial information about the effectiveness of a particular drug on a particular infection rapidly. This will be crucial information for a physician deciding between various drugs available to treat patients with infections where drug resistance may be prevalent. 


\section{Conclusions}

Culture-based methods are the gold standard for diagnosis of bacterial infection and provide crucial information about viability and drug effectiveness. As compared to molecular diagnostic methods, they are low-cost, simple to use, and do not requirement extensive sample preparation and therefore are more suitable for resource-poor settings. However, they typically take one day to four weeks to obtain results due to the dependence on growth and multiplication of the bacteria into colonies for identification. Instead, metabolic monitoring can be used to perform diagnosis of culture-based assays more quickly. In this paper we have developed a simple method to automatically aliquot a sample of various viscosities into thousands of nanoliter volumes and used it to measure metabolic activity of bacteria that are present in them. We demonstrate that the nanoscale volumes have sufficient nutrients to sustain the bacteria for more than $10 \mathrm{~h}$. We show that the metabolic rate can be easily measured in these wells by using an oxygen sensitive fluorophore and that the rate of change of its intensity is proportional to the concentration of the bacteria in the sample. We also show single bacterial cell detection is possible and that the time for detection is greatly reduced if the sample is aliquoted into thousands of small nanoliter wells and measured in parallel. Finally, we demonstrate that the same assay could be used to identify the effectiveness of a drug on that particular infection which provides crucial information to a medical professional in formulating a treatment. Although these results are preliminary and require further validation, they are promising, and these nanowell devices for metabolic monitoring have many potential applications for many industries (i.e., medical and food) and for testing and studying bacteria with rapid, accurate, and effective response.

Acknowledgments: We acknowledge financial support from Grand Challenges Canada through their Rising Stars in Global Health Award, The Canada Research Chairs Program and the Ontario Research Fund, Research Excellence Program. We also acknowledge personnel in the Biophotonics facility, Micro Nanosystems center and Biointerfaces institute at McMaster for space and equipment for conducting this research.

Author Contributions: S.A. contributed to performing of the experiments, discussions and preparing the manuscript. W.W. contributed to performing experiments and discussions. P.R.S. conceived the idea and contributed to the discussion, preparation of the manuscript and response to reviewers.

Conflicts of Interest: The authors declare no conflict of interest.

\section{References}

1. World Health Organization. The Global Burden of Disease. Available online: http://www.who.int/topics / global_burden_of_disease/en/ (accessed on 27 October 2016).

2. Infectious Diseases. The CSIS Global Health Policy Center 2015. Available online: https://www.csis.org/ topics/global-health/infectious-disease (accessed on 27 October 2016).

3. World Health Organization. Tuberculosis. Available online: http://www.who.int/mediacentre/factsheets/ fs104/en/ (accessed on 27 October 2016).

4. Lozano, R.; Naghavi, M.; Foreman, K.; Lim, S.; Shibuya, K.; Aboyans, V.; Abraham, J.; Adair, T.; Aggarwal, R.; Ahn, S.Y.; et al. Global and regional mortality from 235 causes of death for 20 age groups in 1990 and 2010 : A systematic analysis for the Global Burden of Disease Study 2010. Lancet 2012, 380, 2095-2128. [CrossRef]

5. O'Brien, K.L.; Wolfson, L.J.; Watt, J.P.; Henkle, E.; Deloria-Knoll, M.; McCall, N.; Lee, E.; Mulholland, K.; Levine, O.S.; Cherian, T. Burden of disease caused by Streptococcus pneumoniae in children younger than 5 years: Global estimates. Lancet 2009, 374, 893-902. [CrossRef]

6. Pachecker, H.H. The Immigrant's Universe; Xlibris: Bloomington, IN, USA, 2010.

7. Jay, M.T.; Garrett, V.; Mohle-Boetani, J.C.; Barros, M.; Farrar, J.A.; Rios, R.; Abbott, S.; Sowadsky, R.; Komatsu, K.; Mandrell, R.; et al. A multistate outbreak of Escherichia coli O157:H7 infection linked to consumption of beef tacos at a fast-food restaurant chain. Clin. Infect. Dis. 2004, 39, 1-7. [CrossRef] [PubMed]

8. Messelhäusser, U.; Kämpf, P.; Hörmansdorfer, S.; Wagner, B.; Schalch, B.; Busch, U.; Höller, C.; Wallner, P.; Barth, G.; Rampp, A. Culture and molecular method for detection of Mycobacterium tuberculosis complex and Mycobacterium avium subsp. paratuberculosis in milk and dairy products. Appl. Environ. Microbiol. 2012, 78, 295-297. [CrossRef] [PubMed] 
9. Toze, S. PCR and the detection of microbial pathogens in water and wastewater. Water Res. 1999, 33, 3545-3556. [CrossRef]

10. Allegranzi, B.; Nejad, S.B.; Combescure, C.; Graafmans, W.; Attar, H.; Donaldson, L.; Pittet, D. Burden of endemic health-care associated infection in developing countries: Systematic review and meta-analysis. Lancet 2011, 377, 228-241. [CrossRef]

11. Polin, R.A.; Denson, S.; Brady, M.T.; Papile, L.A.; Baley, J.E.; Carlo, W.A.; Cummings, J.J.; Kumar, P.; Tan, R.C.; Watterberg, K.L. Epidemiology and diagnosis of health care-associated infections in the NICU. Pediatrics 2012, 129, e1104-e1109. [CrossRef] [PubMed]

12. Kochi, A. The global tuberculosis situation and the new control strategy of the World Health Organization. Bull. World Health Organ. 2001, 79, 71-75. [CrossRef]

13. Chung, H.J.; Castro, C.M.; Im, H.; Lee, H.; Weissleder, R. A magneto-DNA nanoparticle system for rapid detection and phenotyping of bacteria. Nat. Nanotechnol. 2013, 8, 369-375. [CrossRef] [PubMed]

14. World Health Organization. Cutting-Edge Science and the Future of Tuberculosis Control. Available online: http://www.who.int/bulletin/volumes/85/5/06-035386/en/ (accessed on 27 October 2016).

15. Gracias, K.S.; McKillip, J.L. A review of conventional detection and enumeration methods for pathogenic bacteria in food. Can. J. Microbiol. 2004, 50, 883-890. [CrossRef] [PubMed]

16. World Health Organization. Diagnostics for Tuberculosis: Global Demand and Market Potential. Available online: http:/ / www.who.int/tdr/publications/documents/tbdi.pdf?ua=1 (accessed on 27 October 2016).

17. Lee, H.; Park, J.; Kim, J.; Jung, H.; Kawai, T. Well-oriented nanowell array metrics for integrated digital nanobiosensors. Appl. Phys. Lett. 2006, 89, 113901. [CrossRef]

18. Liang, P.-S.; Park, T.S.; Yoon, J.-Y. Rapid and reagentless detection of microbial contamination within meat utilizing a smartphone-based biosensor. Sci. Rep. 2014, 4, 5953. [CrossRef] [PubMed]

19. Kik, S.V.; Denkinger, C.M.; Casenghi, M.; Vadnais, C.; Pai, M. Tuberculosis diagnostics: Which target product profiles should be prioritised? Eur. Respir. J. 2014, 44, 537-540. [CrossRef] [PubMed]

20. Francois, P.; Tangomo, M.; Hibbs, J.; Bonetti, E.-J.; Boehme, C.C.; Notomi, T.; Perkins, M.D.; Schrenzel, J. Robustness of a loop-mediated isothermal amplification reaction for diagnostic applications. FEMS Immunol. Med. Mic. 2011, 62, 41-48. [CrossRef] [PubMed]

21. Aellen, S.; Que, Y.-A.; Guignard, B.; Haenni, M.; Moreillon, P. Detection of live and antibiotic-killed bacteria by quantitative real-time PCR of specific fragments of rRNA. Antimicrob. Agents Chemother. 2006, 50, 1913-1920. [CrossRef] [PubMed]

22. Sprayberry, K.A.; Robinson, N.E. Robinson's Current Therapy in Equine Medicine; Elsevier: Amsterdam, The Netherlands, 2014.

23. Torres, A.J.; Hill, A.S.; Love, J.C. Nanowell-based immunoassays for measuring single-cell secretion: Characterization of transport and surface binding. Anal. Chem. 2014, 86, 11562-11569. [CrossRef] [PubMed]

24. Papkovsky, D.B.; Dmitriev, R.I. Biological detection by optical oxygen sensing. Chem. Soc. Rev. 2013, 42, 8700-8732. [CrossRef] [PubMed]

25. Arain, S. Microrespirometry with Sensor-Equipped Microtiterplates. Ph.D. Thesis, University of Regensberg, Regensburg, Germany, February 2006.

26. Chen, C.H.; Lu, Y.; Sin, M.L.Y.; Mach, K.E.; Zhang, D.D.; Gau, V.; Liao, J.C.; Wong, P.K. Antimicrobial susceptibility testing using high surface- to-volume ratio microchannels. Anal. Chem. 2010, 82, 1012-1019. [CrossRef] [PubMed]

27. Somoskövi, Á.; Ködmön, C.; Lantos, Á.; Bártfai, Z.; Tamási, L.; Füzy, J.; Magyar, P. Comparison of recoveries of mycobacterium tuberculosis using the automated BACTEC MGIT 960 system, the BACTEC 460 TB System, and Löwenstein-Jensen medium. J. Clin. Microbiol. 2000, 38, 2395-2397. [PubMed]

28. George, W.L.; Sutter, V.L.; Citron, D.; Finegold, S.M. Selective and differential medium for isolation of Clostridium difficile. J. Clin. Microbiol. 1979, 9, 214-219. [PubMed]

29. Rosenfeld, L.; Lin, T.; Derda, R.; Tang, S.K.Y. Review and analysis of performance metrics of droplet microfluidics systems. Microfluid. Nanofluid. 2014, 16, 921-939. [CrossRef]

30. Rettig, J.R.; Folch, A. large-scale single-cell trapping and imaging using microwell arrays. Anal. Chem. 2005, 77, 5628-5634. [CrossRef] [PubMed]

31. Lee, W.C.; Rigante, S.; Pisano, A.P.; Kuypers, F.A. Large-scale arrays of picolitre chambers for single-cell analysis of large cell populations. Lab Chip 2010, 10, 2952-2958. [CrossRef] [PubMed] 
32. Nguyen, Y.H.; Ma, X.; Qin, L. Rapid identification and drug susceptibility screening of ESAT-6 secreting Mycobacteria by a NanoELIwell assay. Sci. Rep. 2012, 2, 635. [CrossRef] [PubMed]

33. Balsam, J.; Ossandon, M.; Bruck, H.; Rasooly, A. Low-cost technologies for medical diagnostics in low-resource settings. Expert. Opin. Med. Diagn. 2013, 7, 243-255. [CrossRef] [PubMed]

34. Miller, A.R.; Davis, G.L.; Oden, Z.M.; Razavi, M.R.; Fateh, A.; Ghazanfari, M.; Abdolrahimi, F.; Poorazar, S.; Sakhaie, F.; Olsen, R.J.; et al. Portable, battery-operated, low-cost, bright field and fluorescence microscope. PLoS ONE 2010, 5, e11890. [CrossRef] [PubMed]

35. Methyl Cellulose: Product Information Sheet. Available online: http://www.sigmaaldrich.com/ content/dam/sigma-aldrich/docs/Sigma/Product_Information_Sheet/2/m0512pis.pdf (accessed on 27 October 2016).

36. Lopez-Vidriero, M.T.; Charman, J.; Keal, E.; De Silva, D.J.; Reid, L. Sputum viscosity: Correlation with chemical and clinical features in chronic bronchitis. Thorax 1973, 28, 401-408. [CrossRef] [PubMed]

37. Taylor, L.C.; Walt, D.R. Application of High-Density Optical Microwell Arrays in a Live-Cell Biosensing System. Anal. Biochem. 2000, 278, 132-142. [CrossRef] [PubMed]

38. Yamada, H.; Mitarai, S.; Aguiman, L.; Matsumoto, H.; Fujiki, A. Preparation of mycobacteria-containing artificial sputum for TB panel testing and microscopy of sputum smears. Int. J. Tuberc. Lung Dis. 2006, 10, 899-905. [PubMed]

39. Keer, J.T.; Birch, L. Molecular methods for the assessment of bacterial viability. J. Microbiolog. Methods 2003, 53, 175-183. [CrossRef]

40. Andrews, J.M. Determination of minimum inhibitory concentrations. J. Antimicrob. Chemother. 2001, 48, 5-16. [CrossRef] [PubMed]

(C) 2016 by the authors; licensee MDPI, Basel, Switzerland. This article is an open access article distributed under the terms and conditions of the Creative Commons Attribution (CC-BY) license (http://creativecommons.org/licenses/by/4.0/). 